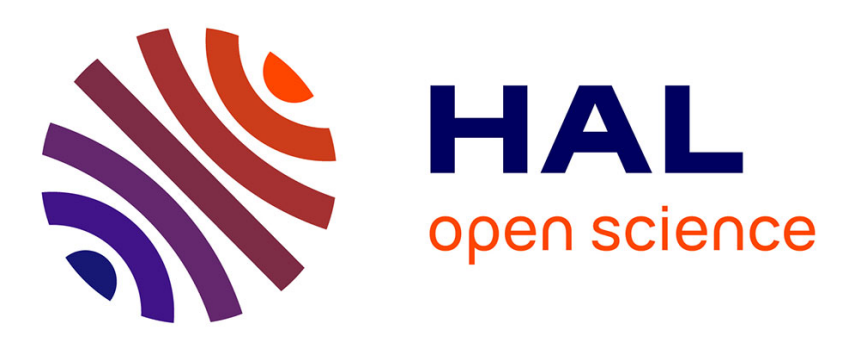

\title{
Hydrogen diffusion and densification in amorphous silicon
}

\author{
M. Vergnat, S. Houssaïni, G. Marchal, Ph. Mangin, C. Vettier
}

\section{To cite this version:}

M. Vergnat, S. Houssaïni, G. Marchal, Ph. Mangin, C. Vettier. Hydrogen diffusion and densification in amorphous silicon. Physical Review B: Condensed Matter and Materials Physics (1998-2015), 1993, 47 (12), pp.7584-7587. 10.1103/PhysRevB.47.7584 . hal-02113408

\section{HAL Id: hal-02113408 \\ https://hal.science/hal-02113408}

Submitted on 28 Apr 2019

HAL is a multi-disciplinary open access archive for the deposit and dissemination of scientific research documents, whether they are published or not. The documents may come from teaching and research institutions in France or abroad, or from public or private research centers.
L'archive ouverte pluridisciplinaire HAL, est destinée au dépôt et à la diffusion de documents scientifiques de niveau recherche, publiés ou non, émanant des établissements d'enseignement et de recherche français ou étrangers, des laboratoires publics ou privés. 


\title{
Hydrogen diffusion and densification in amorphous silicon
}

\author{
M. Vergnat, S. Houssaini, G. Marchal, and Ph. Mangin \\ Laboratoire de Métallurgie Physique et Sciences des Materiaux, \\ Université de Nancy I, Bôte Postale 239, 54506 Vandoeuvre-les-Nancy CEDEX, France \\ C. Vettier \\ Institut Laüe Langevin, Bô̂te Postale 156X, 38042 Grenoble CEDEX, France \\ and European Synchrotron Research Facility, Botte Postale 220, 38043 Grenoble CEDEX, France
}

(Received 19 October 1992)

\begin{abstract}
Hydrogenated amorphous silicon prepared by evaporation onto low-temperature substrates is characterized by a low-density network and by the presence of $\left(\mathrm{SiH}_{2}\right)_{n}$ bonds. By monitoring the decay of the small-angle neutron-scattering intensity during annealing of $\mathrm{Si} / \mathrm{Si}: \mathrm{H} / \mathrm{Si} / \mathrm{Si}: \mathrm{M} / \cdots\left(\boldsymbol{M}=\mathbf{H}_{28} \mathrm{D}_{72}\right)$ multilayers, it is possible to follow simultaneously the densification of the silicon network and the diffusion of the hydrogen atoms.
\end{abstract}

Hydrogen bonding and microstructure in hydrogenated amorphous silicon have been extensively studied in the past few years. Depending on the preparation techniques and on the experimental conditions, films have been prepared with different hydrogen bonding and microstructure. As mentioned by Jackson and Tsai, ${ }^{1}$ two extreme microstructure models can exist. In the first model, films deposited at high deposition rates or at low temperatures exhibit a large number of voids, leading to density deficits as large as $15 \%$ of crystalline silicon. The infrared-absorption spectrum exhibits a band near 2100 $\mathrm{cm}^{-1}$, which is attributed to $\mathrm{Si}-\mathrm{H}$ bonds on the surface of voids and, if associated with modes at $845-890 \mathrm{~cm}^{-1}$, to $\left(\mathrm{SiH}_{2}\right)$ and $\left(\mathrm{SiH}_{2}\right)_{n}$ polysilane configurations. ${ }^{2,3}$ Hydrogen diffuses along the interconnected void surfaces. These hydrogen structures are termed open voids because, when hydrogen is removed, the voids must remain since the interaction between the opposing sides of the voids is too weak to allow a significant reconstruction. In the second model, films are prepared at higher substrate temperatures and the infrared-absorption spectrum shows a band at $2000 \mathrm{~cm}^{-1}$ which is attributed to $\mathrm{Si}-\mathrm{H}$ bonds located within the bulk. In fact, the hydrogen atoms form plateletlike clusters as in hydrogenated crystalline silicon. The platelets are equivalent to closed voids, since these voids must disappear upon hydrogen removal, because the opposing sides of the voids interact strongly and are replaced by $\mathrm{Si}-\mathrm{Si}$ bonds.

In this Brief Report, we present a study of evaporated $a-\mathrm{Si}: \mathrm{H}$ prepared at liquid-nitrogen temperature and characterized by a low-density network and by a very intense infrared band at $2100 \mathrm{~cm}^{-1}$. This material corresponds to the first interconnected void model described above. The aim of this study is to test the previsions of the model concerning the microstructure evolution by following simultaneously the densification of the network and the diffusion of the hydrogen atoms. As shown below, an original way to obtain this information consists of following the temperature evolution of low-angle neutron- or x-ray-diffraction peaks of hydrogenated amorphous silicon multilayers.

Recently, we have shown that the evaporation of silicon under an alternative flow of hydrogen (or deuterium) atoms leads to the formation of periodic amorphous structures of type $\mathrm{Si} / \mathrm{Si}: \mathrm{H} / \mathrm{Si} / \mathrm{Si}: \mathrm{H} / \cdots$ or Si:H/Si:D/Si:H/Si:D/... ${ }^{4}$ The modulations were characterized by low-angle-diffraction peaks in $\mathrm{x}$-ray- or neutron-scattering experiments. As the x-ray-scattering factor from hydrogen is very weak, the low-angle $\mathrm{x}$-raydiffraction peaks in $\mathrm{Si} / \mathrm{Si}: \mathrm{H} / \mathrm{Si} / \mathrm{Si}: \mathrm{H} / \cdots$ multilayers arise from the difference between the high atomic density of silicon and the low atomic density of hydrogenated silicon. On the other hand, as the neutron-coherent scattering amplitudes of $\mathrm{H}$ and $\mathrm{D}$ are large and of opposite sign $\left(b_{H}=-0.374 \times 10^{-12} \mathrm{~cm}, b_{D}=0.667 \times 10^{-12} \mathrm{~cm}\right)$, the modulation of hydrogen and deuterium concentrations can be observed by carrying out neutron-diffraction experiments on $\mathrm{Si}: \mathrm{H} / \mathrm{Si}: \mathrm{D} / \mathrm{Si}: \mathrm{H} / \mathrm{Si}: \mathrm{D} / \cdots$ multilayers. During thermal treatments, the x-ray-diffraction peak observed in $\mathrm{Si} / \mathrm{Si}: \mathrm{H} / \cdots$ multilayers decreases due to the densification of the hydrogen layers, and the neutrondiffraction peak observed in $\mathrm{Si}: \mathrm{H} / \mathrm{Si}: \mathrm{D} / \cdots$ multilayers decreases due to the diffusion of hydrogen and deuterium through the layers. Diffusion coefficients of hydrogen in amorphous silicon have been deduced from the decay of the low-angle neutron-scattering intensity during annealings. ${ }^{5}$

In order to determine simultaneously the thermal stability of the density difference between the layers and of the hydrogen modulation, we carried out low-angle neutron scattering on $\mathrm{Si} / \mathrm{Si}: \mathrm{H} / \mathrm{Si} / \mathrm{Si}: M / \cdots$ multilayers, where $M$ is the mixture $\mathrm{H}_{28} \mathrm{D}_{72}$ so that the average neutron-coherent scattering amplitude of $\mathrm{H}$ and $M$ is zero $\left(b_{\mathrm{H}}=-b_{M}\right)$. Such a system could be compared to an antiferromagnetic material, where the main peak is due only to the nuclear modulation (here the atomic silicon density) and the superstructure peak is due only to the magnetic modulation (here the hydrogen modulation).

The multilayers were prepared by evaporation of sil- 
icon from an electron-gun crucible. The deposition rate of silicon was controlled and measured by a quartz microbalance system. The expected deposition rate of silicon on the substrates was $1.3 \AA / \mathrm{s}$. The substrates were float-glass strips which were kept at liquid-nitrogen temperature during the deposition process. Hydrogen and the mixture $\mathrm{H}_{28} \mathrm{D}_{72}$ were introduced in the chamber through a tungsten tube heated at $2000 \mathrm{~K}$ in order to decompose the molecular flow. ${ }^{6}$ The pressure sequences were $7 \times 10^{-5}$ Torr during $30 \mathrm{~s}$ when silicon was evaporated under a flow of hydrogen or deuterium atoms, and $2 \times 10^{-6}$ Torr during $30 \mathrm{~s}$ when silicon was evaporated without gaseous flow, etc. It was not possible to lower the pressure in a reasonable time below $2 \times 10^{-6}$ Torr between two sequences of "hydrogenation." The total number of layers was 100 .

An infrared transmission spectrum (Fig. 1) of a bulk hydrogenated sample prepared with such experimental conditions shows the polysilane features which are characteristics of the interconnected void model: an intense absorption band at $2100 \mathrm{~cm}^{-1}$ (stretching modes), a doublet with relatively sharp features at 890 and 845 $\mathrm{cm}^{-1}$ [wagging and scissors modes of $\left(\mathrm{SiH}_{2}\right)_{n}$ groups], and the band at $630 \mathrm{~cm}^{-1}$ (rocking modes). The band at $2000 \mathrm{~cm}^{-1}$ corresponding to stretching modes of monohydride $\mathrm{SiH}$ groups is absent. Moreover, absorption bands centered at 980 and $1050 \mathrm{~cm}^{-1}$ indicate a low oxygen contamination of the samples.

The low-angle neutron-scattering experiments were performed on the D10 instrument of the Institut Laüe Langevin. The instrument was in the triple-axis configuration set at zero energy with a graphite analyzer to reduce the background at low angles. The neutron wavelength was $2.36 \AA$. The monochromator and analyzer crystal were (002) graphite and a PG filter was used. The data presented here were obtained with $10 \mathrm{~min}$ collimation on each side of the samples.

The low-angle neutron-scattering pattern of the $\mathrm{Si} / \mathrm{Si}: \mathrm{H} / \mathrm{Si} / \mathrm{Si}: M / \cdots$ multilayers is represented in Fig. 2(a). With a bilayer thickness equal to $95 \AA$, the peak located at $0.065 \AA^{-1}$ is due to the silicon density modulation (the wavelength is $95 \AA$ ) and the superstructure peak located at $0.0325 \AA^{-1}$ arises from the isotope modulation (the wavelength is $190 \AA$ ). In a first experiment, we followed the evolution of the low-angle neutron-scattering patterns versus temperature with a heating rate of $4{ }^{\circ} \mathrm{C} / \mathrm{h}$ and we measured the integrated intensities $I_{1 / 2}(t)$ and

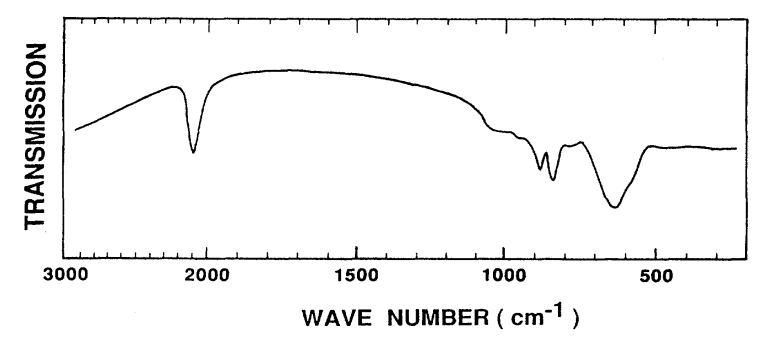

FIG. 1. Infrared transmission spectrum of evaporated $a$-Si:H deposited at $77 \mathrm{~K}$.
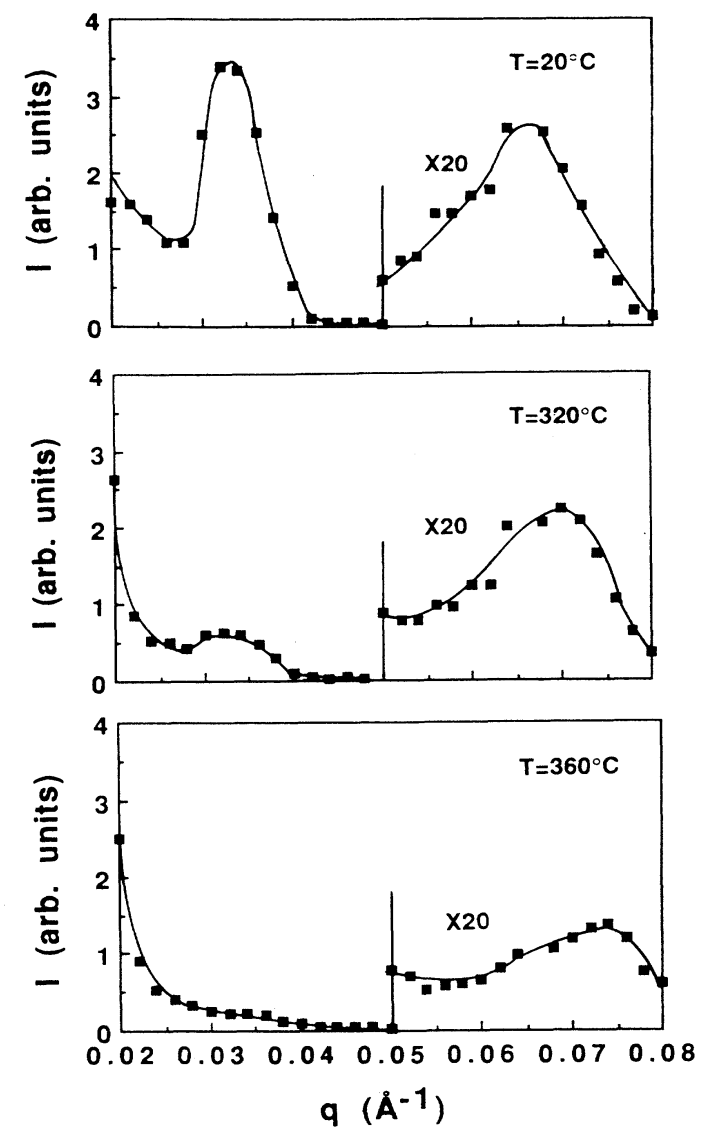

FIG. 2. Evolution of the low-angle neutron-scattering pat tern of $\mathrm{Si} / \mathrm{Si}: \mathrm{H} / \mathrm{Si} / \mathrm{Si}: M / \cdots\left(\boldsymbol{M}=\mathrm{H}_{28} \mathrm{D}_{72}\right)$ multilayers for different temperatures.

$I_{1}(t)$ of the superstructure "hydrogen" peak and of the "density" peak, respectively, versus temperature (Fig. 3). At $320^{\circ} \mathrm{C}$ [Fig. 2(b)], the superstructure peak always strongly decreases when the density peak has the same intensity. At $360^{\circ} \mathrm{C}$ [Fig. 2(c)], the hydrogen peak almost completely disappears whereas the density peak is always

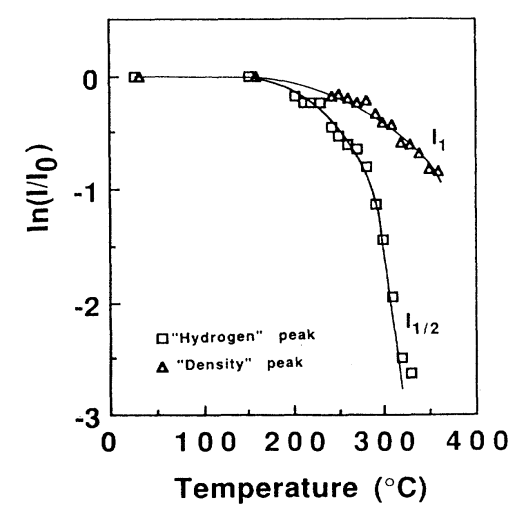

FIG. 3. Evolution vs temperature of the intensity $I(t)$ of the superstructure "hydrogen" peak and of the "density" peak. $I_{0}$ is the initial intensity. The heating rate was $4^{\circ} \mathrm{C} / \mathrm{h}$. 


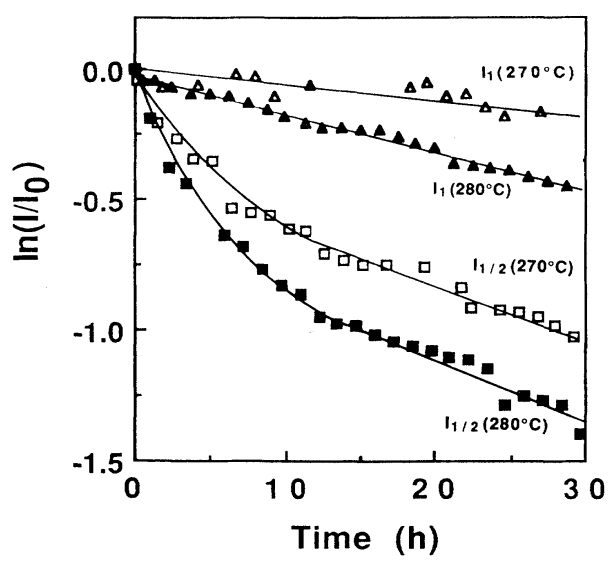

FIG. 4. Evolution vs time of the intensity of the superstructure "hydrogen" peak ( $\left.\square: 270^{\circ} \mathrm{C} ; \mathbf{\square}: 280^{\circ} \mathrm{C}\right)$ and of the "density" peak $\left(\triangle: 270^{\circ} \mathrm{C} ; \Delta: 280^{\circ} \mathrm{C}\right)$ for isothermal annealings at 270 and $280^{\circ} \mathrm{C}$.

visible but displaced toward the higher-angle values. It is clear that the hydrogen atoms diffuse before the densification of the amorphous network. The two phenomena do not take place simultaneously, which is in agreement with the interconnected void model. Moreover, as the "density" peak is displaced from $0.065 \AA^{-1}$ at room temperature to $0.072 \AA^{-1}$ at $360{ }^{\circ} \mathrm{C}$, we can deduce that the relative variation of the $\mathrm{Si}: \mathrm{H}$ layer thickness (i.e., the relative density variation) is about $20 \%$.

In a second experiment, the time evolution of the lowangle neutron-scattering patterns was followed during isothermal treatments. The experimental plots of $\ln I(t) / I_{0}$ versus annealing time $t$ are shown in Fig. 4 for temperatures of 270 and $280^{\circ} \mathrm{C}$. For each temperature, the intensity of the "hydrogen" peak decreases more rapidly than that of the "density" peak.

Diffusion coefficients of hydrogen were obtained by measuring the decay of the low-angle neutron-scattering intensity $I_{1 / 2}$ during annealing. If the hydrogen diffusivity $D_{\mathrm{H}}$ is assumed to be independent of time and composition, $D_{\mathrm{H}}$ can be obtained from the decay rate of the intensity $I(t)$ by the formula ${ }^{7,8}$

$$
D_{\mathrm{H}}=-\frac{1}{2 q_{1 / 2}^{2}} \frac{d \ln I_{1 / 2}(t) / I_{0}}{d t},
$$

where $q_{1 / 2}$ is the scattering vector of the diffraction peak and $I_{0}$ is the initial intensity. Experimentally, the neutron-diffracted intensity shows a fast initial decrease, followed by a slower decrease. The diffusion coefficient is therefore time dependent, as was first suggested by Street et al. ${ }^{9}$ However, as this slope diminishes only by a factor 2 during the same annealing, we have determined, in a first approximation, diffusion coefficients from the average slopes of the long-time portion of the plots. The diffusivity values are $D_{\mathrm{H}}\left(270^{\circ} \mathrm{C}\right)=2.2 \times 10^{-19} \mathrm{~cm}^{2} / \mathrm{s}$ and $D_{\mathrm{H}}\left(280^{\circ} \mathrm{C}\right)=3.6 \times 10^{-19} \mathrm{~cm}^{2} / \mathrm{s}$. They are very close to the values of diffusivity obtained from $\mathrm{Si}: \mathrm{H} / \mathrm{Si}: \mathrm{D}$ multilayers. $^{5}$

From these two values, a plot of $\ln D_{\mathrm{H}}$ versus $1 / k T$ could not give an accurate determination of the activation energy. Also, as suggested by Jackson and Tsai, ${ }^{1}$ the activation energy, which corresponds to the depth of the diffusion traps compared to the transport level, can be more reliably determined by assuming the prefactor equal to the usual value $D_{0}=10^{-3} \mathrm{~cm}^{2} / \mathrm{s}$. The activation energies derived from this procedure at 270 and $280^{\circ} \mathrm{C}$ are both equal to $1.7 \mathrm{eV}$. This value is rather large and corresponds to deep traps, which could be the (SiHHSi) structures. ${ }^{1,10}$ This large activation energy and the corresponding low diffusion coefficients also agree with the evidence of Shinar et al. ${ }^{11}$ that, with the experimental resolution of secondary-ion-mass spectroscopy (SIMS) experiments, there is virtually no diffusion in some void-rich samples.

The decay of the second peak and its displacement toward the higher-angle values during annealing correspond to a collapse of the voids in the low-density layers and therefore to displacements of silicon atoms. By applying the same procedure as that for the "hydrogen" peak, the diffusion coefficient of the silicon atoms has been obtained. The values $D_{\mathrm{Si}}\left(270^{\circ} \mathrm{C}\right)=1.7 \times 10^{-20}$ $\mathrm{cm}^{2} / \mathrm{s}$ and $D_{\mathrm{Si}}\left(280^{\circ} \mathrm{C}\right)=4.5 \times 10^{-20} \mathrm{~cm}^{2} / \mathrm{s}$ are an order of magnitude lower than the corresponding values $D_{\mathrm{H}}$. They confirm the fact that the densification of the structure is slower than the diffusion of hydrogen atoms.

In conclusion, by using low-angle neutron scattering on $\mathrm{Si} / \mathrm{Si}: \mathrm{H} / \mathrm{Si} / \mathrm{Si}: M / \cdots\left(M=\mathrm{H}_{28} \mathrm{D}_{72}\right)$ multilayers and by monitoring the decay of the intensity of the main peak corresponding to the atomic silicon density and of the superstructure peak corresponding to the hydrogen modulation, the diffusion coefficient of hydrogen was measured at 270 and $280^{\circ} \mathrm{C}$ in evaporated amorphous silicon, and the trap depth was estimated to be equal to $1.7 \mathrm{eV}$. Moreover, we have shown that the densification corresponds to silicon diffusivities which are an order of magnitude lower than the hydrogen diffusivities. Hence, the diffusion of the hydrogen atoms occurs before the densification of the structure, as predicted by the interconnected void model.

The Laboratoire de Métallurgie Physique et Sciences des Matériaux is "Unité Associée au Centre National de la Recherche Scientifique No. 155."
${ }^{1}$ W. B. Jackson and C. C. Tsai, Phys. Rev. B 45, 6564 (1992).

2P. Gupta, V. L. Colvin, and S. M. George, Phys. Rev. B 37 , 8234 (1988).

${ }^{3}$ G. Lucovsky, J. Non-Cryst. Solids 76, 173 (1985).

${ }^{4}$ M. Vergnat, S. Houssaïni, C. Dufour, A. Bruson, G. Marchal,
Ph. Mangin, R. Erwin, J. J. Rhyne, and C. Vettier, Phys. Rev. B 40, 1418 (1989).

${ }^{5}$ M. Vergnat, S. Houssaïni, C. Dufour, A. Bruson, G. Marchal, Ph. Mangin, R. Erwin, J. J. Rhyne, and C. Vettier, Europhys. Lett. 14, 457 (1991). 
${ }^{6}$ M. Vergnat, G. Marchal, and M. Piecuch, Rev. Phys. Appl. 22, 1803 (1987).

7J. Dumond and J. P. Youtz, J. Appl. Phys. 11, 357 (1940).

${ }^{8}$ H. E. Cook and J. E. Hilliard, J. Appl. Phys. 40, 2191 (1969).

${ }^{9}$ R. A. Street, C. C. Tsai, J. Kakalios, and W. B. Jackson, Phi- los. Mag. B 56, 305 (1987).

${ }^{10}$ W. B. Jackson, Solar Energy Mater. 23, 239 (1991).

${ }^{11}$ J. Shinar, R. Shinar, S. Mitra, and J. Y. Kim, Phys. Rev. Lett. 62, 2001 (1989). 